\title{
Metal analysis of horse bits using X-ray fluorescence (XRF)
}

\author{
Conny Herholz', Markus Flisch², Damiana Rinaldi', Margret Dreier ${ }^{3}$, Albert Ammann ${ }^{2}$ and Christoph Kopp \\ I School of Agricultural, Forest and Food Sciences HAFL, Zollikofen, Switzerland \\ ${ }^{2}$ Bern Cantonal Laboratory, Environmental Security Division, Bern, Switzerland \\ ${ }^{3}$ Swiss Equestrian Sport Federation, SVPS-FSSE, Bern, Switzerland
}

\begin{abstract}
Summary: Stainless steel and different brass alloys are materials commonly used for bits in equestrian sports. Sweet iron bits for horses are the current trend as they develop superficial rust which tastes sweet and enhances the horse's saliva production. This study focusses on the metal analysis of different bits ( $n=103)$ using X-ray fluorescence (XRF) spectrometry. The analysed elements were clustered statistically in order to define different alloy groups with specific element ranges. In a field test, changes in the iron content and weight losses of both sweet iron $(n=10)$ and conventional $(n=9)$ metallic bits due to normal wear were analysed over 90 days. Fourteen chemical elements accounted for at least $97.07 \%$ (median: $99.85 \%$, mean: 99.70\%) of the weight of the bits. Of the 103 bits studied, 93 could be attributed to one of the six principal alloy groups identified by the statistical clustering method. Copper and zinc were important elements in the definition of the alloy groups and their proportions characterised most of the bits. During 90 days of normal wear, no significant variation of the percentage iron content of the bits was observed, neither for the conventional bits $(p=0.53)$ nor for the sweet iron ones $(p=0.41)$. However, significant weight losses occurred in both groups, averaging $0.28 \mathrm{~g}(\mathrm{p}=0.04)$ in the conventional group and $0.2 \mathrm{~g}(\mathrm{p}=0.02)$ in the sweet iron group. Based on the results of the metal analysis by XRF and the field test carried out to observe changes occurring during normal wear, there is no reason to expect a toxic release of iron into the horse's mouth from sweet iron bits.
\end{abstract}

Keywords: horse, bits, sweet iron, alloy, metal analysis, XRF spectrometry

Citation: Herholz C., Flisch M., Rinaldi D., Dreier M., Ammann A., Kopp C. (2019) Metal analysis of horse bits using X-ray fluorescence (XRF). Pferdeheilkunde 35, 234-239; DOI 10.21836/PEM20190304

Correspondence: Prof. Dr. Conny Herholz, School of Agricultural, Forest and Food Sciences HAFL, Länggasse 85, 3052 Zollikofen, Switzerland; conny.herholz@bfh.ch

Received: February 14, 2019 | Accepted: April 2, 2019

\section{Introduction}

In equestrian sports riders and trainers want their horses to work "on the bit" (McGreevy et al. 2010), accept the bit easily and have an overall high saliva production (Guzzo et al. 2018). Stainless steel or different brass alloys are materials commonly used in bits (Guzzo et al. 2018, Anonymus 2019b). Sweet iron bits for horses are the current trend. The blue colour of the bit is the result of a thermal treatment of its metallic surface, which is heated to around $300^{\circ} \mathrm{C}$ causing so-called annealing colours develop. In contact with the air humidity, sweet iron bits develop superficial rust, which tastes sweet and enhances the horse's saliva production. This is thought to make horses accept the bit more easily.

Direct contact with metals can cause allergies, while their absorption through the skin, mucous membranes or the intestinal tract may be harmful to health. In the Swiss food law, maximal allowable contents of potential allergenic or health threatening substances are defined in the regulations on materials in contact with humans. In the veterinary field, there are no special requirements, for example for halters, bridles or bits. Bits in particular, depending on their metallic composition, could potentially cause allergies or damage health.

The current study focusses on the metal analysis by X-ray fluorescence (XRF) of different bits available on the Swiss market, with a special focus on easily corrodible sweet iron bits and conventional metallic bits. The results were clustered statistically in order to define different alloy groups with specific element ranges. A 90-day field test was carried out on sweet iron and conventional metallic bits in order to investigate changes in the iron content and weight loss due to normal wear.

\section{Materials and Methods}

\section{Metal analysis of bits}

Metal analysis was performed on 11 sweet iron (one brand) and 92 conventional bits ( 8 different brands). Nine of the sweet iron and 10 of the conventional bits which were in use were included in the study of the changes in the iron content and weight over 90 days. The analysis was performed by XRF using a hand-held scanner (Niton XL3t/Bruker Titan S1 800), as described by Melquiades and Appoloni, (2004) and Hull (2017). The scanner was positioned evenly on the bit for at least 15 seconds. Three locations were analysed on each bit, one on the front and one on the back and one on the joint of the bit (Fig. 1). All bits were tested unilaterally on one half only, as sample measurements showed no substantial differences between the two parts of the bits. The rings of the bits were excluded from analysis, as they have no or only minor contact with the horse's teeth or saliva. Since the spatial variability was negligible, the three measurements on the bits were averaged. 
Analysis of changes in the iron content and weight losses due to normal wear

Nine sweet iron and 10 conventional bits were analysed over a period of 90 days, regarding possible changes in the iron content and weight losses from normal wear. The test group of horses with conventional metallic bits were used for both dressage and jumping and all horses were usually ridden by more than one rider. All conventional metallic bits were in use for several months before analysis (6-42 months, average 24.6 months). In the test group of horses ridden with sweet iron bits, five horses were used for dressage and jumping, and four horses for dressage only. Two of the jumping and dressage horses were regularly ridden by different riders, all the other horses were ridden by only one person. All sweet iron bits were in use for several months before testing (6-36 months, average 20 months). During the 90days test period all horses were ridden by two different people at most. XRF scans were performed on three locations of the dry and clean bits on days $0,28,60$ and 90, as described above. The weight of the dry and clean bits was determined using a scale with a precision of $0.1 \mathrm{~g}$ and a measurement inaccuracy of $0.02 \%$ (Beurer KS 36) on days $0,28,60$ and 90 .

\section{Statistical analysis}

Analysis of metallic composition, definition of alloys

To avoid measurement artefacts, we focussed on 14 chemical elements (Table 1) whose combined weight accounts for at least $97.07 \%$ (median: $99.85 \%$, mean: $99.70 \%$ ) of the bit weight. Summary statistics of element percentages were calculated, stratified by bit type (conventional/sweet iron). Since a literature research produced no commonly accepted alloy definition, we chose the following data-based approach to identify alloys. A subset of nine elements (Table 2) which we had defined subjectively as potentially important was chosen. Hierarchical clustering with the Manhattan metric and single linkage was used to cluster the data. We tried to obtain a cluster solution which did not consist of too many small clusters. Several variants were tried and a solution with 15 clusters was chosen, with five clusters consisting of 11 or more observations, one cluster with four observations and eight single-observation clusters. Inside each cluster, the distribution of the nine elements was examined and the range of the most prominent one to three elements was taken to characterise alloys.

\section{Weight and iron content loss}

Descriptive statistics of the bit weights (in g) and iron contents (in \%) were computed and, in view of the small differences between adjacent time points, only the difference "last measurement - first measurement" was analysed. We separately calculated a t-test (with associated confidence interval) to test the null hypothesis that the mean difference is zero for the 10 conventional and the 9 sweet iron bits. Due to the small sample sizes, the results were validated with an exact Wilcoxon signed rank test. All statistical analyses were performed using $R$ version 3.5.0 ( $R$ Core Team 2018).

\section{Results}

Metal analysis of the bits available on the Swiss market

The metallic composition (in \%) of the 14 main elements of the conventional and sweet iron bits analysed by XRF is shown in Table 1.

Table 1 Composition in \% of new, not used conventional and sweet iron bits for the 14 main elements analysed by XRF | Zusammensetzung (in \%) bei neven, unbenutzten konventionellen und bei Sweet Iron-Gebissen hinsichtlich der 14 analysierten Hauptelemente

\begin{tabular}{|c|c|c|c|c|c|c|c|c|c|c|}
\hline & \multicolumn{5}{|c|}{ Conventional bits $(n=92)$} & \multicolumn{5}{|c|}{ Sweet Iron bits $(n=11)$} \\
\hline & $\min$ & $\max$ & mean & median & sd & $\min$ & $\max$ & mean & median & $\mathrm{sd}$ \\
\hline $\mathrm{Ti}$ & 0.0 & 99.6 & 1.1 & 0.0 & 10.4 & 0.0 & 0.0 & 0.0 & 0.0 & 0.0 \\
\hline $\mathrm{Cu}$ & 0.0 & 97.2 & 47.7 & 71.9 & 40.2 & 0.0 & 0.3 & 0.1 & 0.1 & 0.1 \\
\hline $\mathrm{Ni}$ & 0.0 & 90.2 & 4.6 & 0.1 & 9.9 & 0.1 & 1.0 & 0.2 & 0.1 & 0.3 \\
\hline $\mathrm{Fe}$ & 0.0 & 74.6 & 28.4 & 1.9 & 34.2 & 93.9 & 98.2 & 97.0 & 97.6 & 1.3 \\
\hline $\mathrm{Zn}$ & 0.0 & 39.2 & 7.0 & 1.4 & 8.7 & 0.0 & 0.0 & 0.0 & 0.0 & 0.0 \\
\hline $\mathrm{Cr}$ & 0.0 & 18.3 & 6.7 & 0.1 & 8.3 & 0.0 & 1.1 & 0.2 & 0.1 & 0.3 \\
\hline $\mathrm{Mn}$ & 0.0 & 10.7 & 2.3 & 0.7 & 3.4 & 0.5 & 1.4 & 0.8 & 0.8 & 0.2 \\
\hline $\mathrm{Al}$ & 0.0 & 6.9 & 0.7 & 0.3 & 1.2 & 0.0 & 0.1 & 0.0 & 0.0 & 0.0 \\
\hline $\mathrm{Sn}$ & 0.0 & 5.1 & 0.1 & 0.0 & 0.6 & 0.0 & 0.0 & 0.0 & 0.0 & 0.0 \\
\hline $\mathrm{Mg}$ & 0.0 & 3.5 & 0.2 & 0.0 & 0.5 & 0.0 & 0.0 & 0.0 & 0.0 & 0.0 \\
\hline $\mathrm{Si}$ & 0.0 & 2.6 & 0.6 & 0.3 & 0.6 & 0.4 & 1.7 & 0.8 & 0.7 & 0.4 \\
\hline Mo & 0.0 & 2.2 & 0.1 & 0.0 & 0.2 & 0.0 & 0.2 & 0.2 & 0.1 & 0.3 \\
\hline$P$ & 0.0 & 1.4 & 0.3 & 0.2 & 0.3 & 0.2 & 2.0 & 0.8 & 0.6 & 0.6 \\
\hline $\mathrm{Pb}$ & 0.0 & 1.4 & 0.1 & 0.0 & 0.2 & 0.0 & 0.00 & 0.0 & 0.0 & 0.0 \\
\hline
\end{tabular}

$\mathrm{Ti}=$ Titanium, $\mathrm{Cu}=$ Copper, $\mathrm{Ni}=$ Nickel, $\mathrm{Fe}=$ Iron, $\mathrm{Zn}=\mathrm{Zinc}, \mathrm{Cr}=$ Chromium, $\mathrm{Mn}=$ Manganese $, \mathrm{Al}=\mathrm{Aluminium}, \mathrm{Sn}=\mathrm{Tin}, \mathrm{Mg}=\mathrm{Magnesium}, \mathrm{Si}=\mathrm{Silicon}, \mathrm{Mo}=\mathrm{Molybden}-$ um, $\mathrm{P}=$ Phosphorus, $\mathrm{Pb}=$ Leadmin = minimum, $\max =$ maximum, $\mathrm{sd}=$ standard deviation 
On average, copper (47.67\%), iron (28.35\%), zinc $(6.96 \%)$, chromium $(6.73 \%)$ and nickel $(4.60 \%)$ were the main elements found in the conventional bits. The highest contents found in conventional bits were $99.6 \%$ for titanium, $97.2 \%$ for copper, $90.2 \%$ for nickel and $74.6 \%$ for iron.

The sweet iron bits could clearly be distinguished from the conventional bits solely by their iron content, which averaged $97 \%$ (minimum $93.9 \%$ and maximum $98.2 \%$ ), while all other elements were present in amounts below $1 \%$. Zinc, lead and manganese were not found in the sweet iron bits.

Of the 103 bits studied, 93 could be attributed to one of the six principal alloy groups identified by the statistical clustering method (Table 2). Copper and zinc were important elements in the definition of the alloy groups and their proportions characterised most of the bits (Fig. 2). Alloy groups 2 and 4 overlapped due to zero or minor percentages of copper and zinc, typical of metals like steel or stainless steel (Fig. 2).

Analysis of changes in the iron content and weight losses of bits by normal wear

The iron content (in \%) of conventional $(n=10)$ and sweet iron $(n=9)$ bits over 90 days during normal wear is shown in Table 3. Only a small systematic variation of the iron content over days 0, 28, 60 and 90 was observed in both the conventional and the sweet iron bits. The differences were not

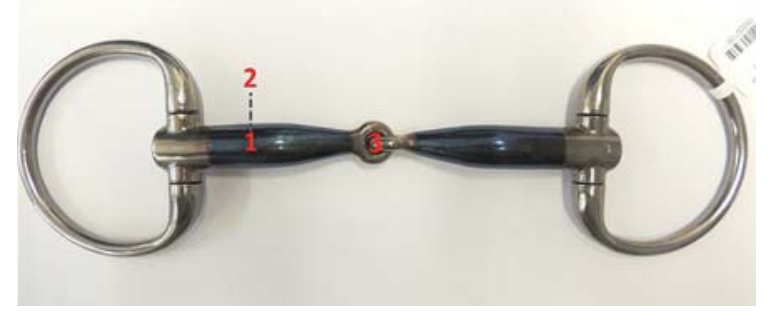

Fig. 1 Sweet iron bit and locations of the XRF scans. | Sweet Iron-Gebiss und Lokalisation der XRF-Scans.

$1=$ XRF scan on the front of the bit, $2=X R F$ scan on the back of the bit, $3=$ XRF scan on the joint of the bit significant, either for the conventional $(p=0.53)$ bits or for the sweet iron $(p=0.41)$ bits. Conversely, the weight loss was significant in both groups, with $p=0.04$ for the conventional bits and $p=0.02$ for the sweet iron bits. The average weight loss was $0.28 \mathrm{~g}$ in the conventional group and $0.2 \mathrm{~g}$ in the sweet iron group (Table 4).

\section{Discussion}

XRF spectrometry is a simple and reliable method to analyse the metallic composition of bits. This technique has been applied to identify the metallic components of different alloys before (Gigante and Cesaro 1998, Longoni et al. 1993) and has been shown to give reliable results after 30 seconds of scanning (Hull 2017). In the present study, stable results for the metallic composition of commercial bits were already ob-

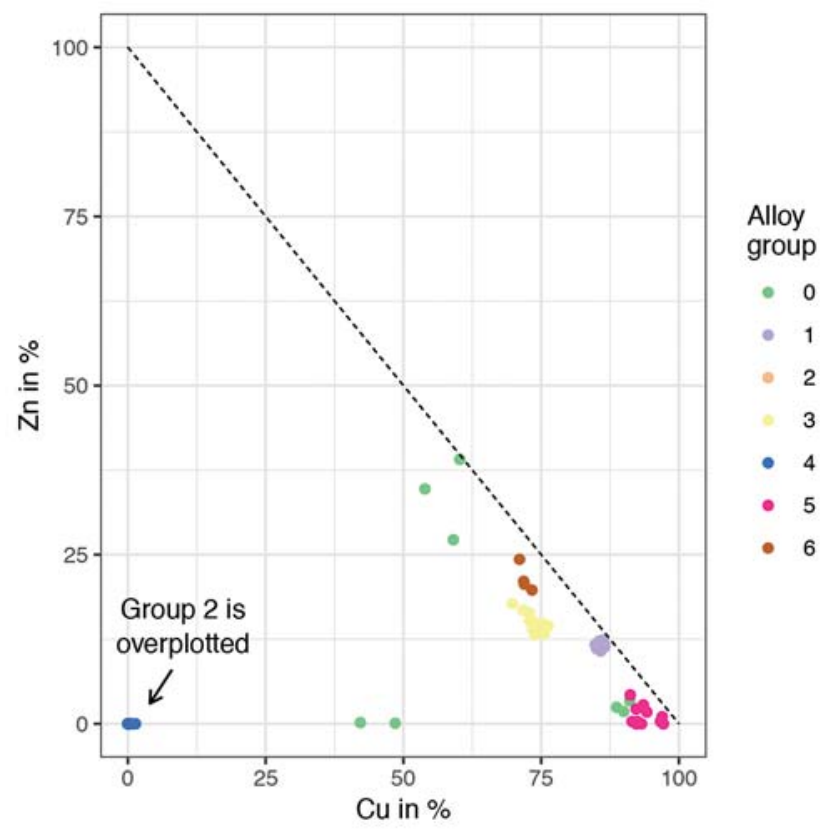

Fig. 2 Copper and zinc proportions characterising different alloy groups of metallic bits. | Kupfer- und Zinkgehalte charakterisieren verschiedene Gruppen von Legierungen bei metallischen Gebissen.

Table 2 Alloy groups and bits $(n=103)$ categorised using the clustering method and the range (\%) of nine important elements identified | Legierungsgruppen und Gebisse $(n=103)$ wurden mithilfe der Cluster-Methode kategorisiert und der Bereich (\%) von 9 wichtigen Elementen ermittelt

\begin{tabular}{|c|c|c|c|c|c|c|c|c|c|}
\hline \multirow[t]{2}{*}{ Alloy group } & \multicolumn{9}{|c|}{ Range of elements (\%) } \\
\hline & $\mathrm{Al}$ & $\mathrm{Cr}$ & $\mathrm{Cu}$ & $\mathrm{Fe}$ & $M n$ & $\mathrm{Ni}$ & $\mathrm{Si}$ & Sn & $\mathrm{Zn}$ \\
\hline $1(n=13)$ & $0.0-0.2$ & $0.0-0.1$ & $84.8-86.5$ & $0.0-0.2$ & $0.0-0.0$ & $0.0-0.0$ & $1.2-2.6$ & $0.0-0.0$ & $10.8-12.4$ \\
\hline $2(n=11)$ & $0.0-0.1$ & $0.0-1.1$ & $0.0-0.3$ & $93.9-98.3$ & $0.5-1.4$ & $0.0-1.0$ & $0.4-1.7$ & $0.0-0.0$ & $0.0-0.0$ \\
\hline $3(n=19)$ & $0.0-1.5$ & $0.0-0.3$ & $69.8-76.2$ & $0.0-0.7$ & $5.6-10.7$ & $0.0-3.8$ & $0.0-0.4$ & $0.0-0.2$ & $13.1-17.8$ \\
\hline $4(n=35)$ & $0.0-0.5$ & $14.5-18.3$ & $0.0-1.4$ & $66.3-74.6$ & $0.4-5.9$ & $5.8-12.2$ & $0.0-2.5$ & $0.0-1.1$ & $0.0-0.0$ \\
\hline $5(n=11)$ & $0.0-3.2$ & $0.0-0.1$ & $91.2-97.2$ & $0.0-4.3$ & $0.0-0.1$ & $0.0-0.1$ & $0.0-1.8$ & $0.0-0.3$ & $0.0-4.3$ \\
\hline $6(n=4)$ & $1.2-1.7$ & $0.0-0.0$ & $71.0-73.3$ & $1.2-2.4$ & $1.4-2.9$ & $0.0-0.0$ & $0.0-0.1$ & $0.0-0.5$ & $19.8-24.3$ \\
\hline $\begin{array}{l}\quad 0(n=10) \\
\text { Bits which do not } \\
\text { belong to group } \\
1-6\end{array}$ & $0.0-6.9$ & $0.0-8.4$ & $0.0-91.1$ & $0.0-35.6$ & $0.0-0.5$ & $0.0-90.2$ & $0.0-2.2$ & $0.0-5.1$ & $0.0-39.2$ \\
\hline
\end{tabular}

The dominant elements in each alloy group are in boldface 
tained after 3 seconds, so a scanning duration of 15 seconds was chosen to ensure reliability. Conventional bits were predominantly composed of copper and zinc alloys or iron alloys. Only two titanium bits were included in the study $(99.59 \% \mathrm{Ti}$, sd 10.4\%). Compared to steel, titanium has a $40 \%$ lower density and is therefore lighter (Liv et al. 2005). Titanium is used for horse bits due to its high resistance to mechanical compression and its lightness and it has been found to cause a smaller temperature increase at the muzzle and neck compared to stainless steel (Guzzo et al. 2018).

While the XRF analysis allowed to differentiate between sweet iron and conventional bits based on the iron content, it was necessary to include multiple elements in order to separate conventional bits into different alloy groups. The percentage ranges of the elements in various alloy groups found in the literature (Anonymus 2019a) is much wider and was not useful for the alloy group definition in our study, due to overlaps. Hierarchical clustering of the data resulted in 6 main groups, which corresponded to commercial alloys, i.e. Aurigan, a copper-zinc-silicon alloy, sweet iron (steel), a mainly iron based alloy, SENSOGAN®, a copper-zinc-manganese alloy, stainless steel, an iron-chromium-nickel alloy, Argentan, a copper-zinc-nickel alloy, and brass, a copper-zinc alloy. The main components of alloy group 4 was iron (66.3-74.6\%), as well as chromium (14.3-18.3\%) and nickel (5.8-12.2\%, Table 2), as in stainless steels. With the XRF spectrometry, the stainless steels bits could be identified as austenitic steels which acquire their austenitic structure primarily by the addition of nickel (McGuire 2001). In the literature, a chromium content between 16 and $25 \%$ is reported (McGuire 2001), which contributes to their high resistance to corrosion. Stainless steel has been reported as the most widespread material for bits in modern times (Esterson 2014).

Two bits of the same brand contained high nickel and low iron concentrations (respectively $90.2 \% \mathrm{Ni}$ and $8.0 \% \mathrm{Fe}$, and $71.4 \% \mathrm{Ni}$ and $27.6 \% \mathrm{Fe}$ ), while all other bits had nickel concentrations below $13 \%$. Nickel is the major cause of allergic contact dermatitis in the general population, both among children and adults (Torres et al. 2009). However, no toxicity studies were identified for horses (Nazifi et al. 2017). Studies on nickel release and allergic contact dermatitis from nickel-plated metals and stainless steels showed that low-sulphur stainless steel grades ( $<<$ or $=0.007 \%$ ) release less than $0.03 \mu \mathrm{g} / \mathrm{cm}^{2} /$ week of nickel in acid artificial sweat and elicit no reactions in human patients already sensitised to nickel

Table 3 Mean iron (Fe) content (\%) of conventional $(n=10)$ and sweet iron $(n=9)$ bits over 90 days during normal wear. | Mittlerer Eisengehalt (\%) von konventionellen $(n=10)$ und von Sweet Iron-Gebissen $(n=9)$ über 90 Tage bei normalem Gebrauch

\begin{tabular}{c|cc|cc}
\hline Day & \multicolumn{2}{|c|}{ Conventional bits $(n=10)$} & \multicolumn{2}{c}{ Sweet Iron bits $(n=9)$} \\
\hline & Mean Fe \% & sd & Mean Fe \% & sd \\
\hline 0 & 0.24 & 0.16 & 97.06 & 1.39 \\
28 & 0.32 & 0.17 & 96.88 & 1.69 \\
60 & 0.26 & 0.18 & 96.49 & 1.62 \\
90 & 0.26 & 0.18 & 97.50 & 0.94 \\
\hline
\end{tabular}

$\mathrm{Fe}=$ iron, $\mathrm{sd}=$ standard deviation
(Haudrechy et al. 1997, Yuan et al. 2015). Assuming a nickel release rate of $0.03 \mu \mathrm{g} / \mathrm{cm}^{2} /$ week from nickel-containing bits, allergic reactions in horses are very unlikely. However, clinical trials showed that horses in contact with nickel-containing bits do, in single cases, develop vesicles on mucous membranes in the mouth (Hermann, personal communication). Nickel as feed supplement (1-22 $\mu \mathrm{g} \mathrm{Ni} / \mathrm{kg}$ bodyweight/day) has gained attention in equine sport drug testing as an erythropoiesis-stimulating agent (Thevis et al. 2016), but these doses far exceed the possible nickel release from horse bits.

The bits of groups 1,3 and 6 were found to be made of three different brass alloys (Table 2). Brass is a metal that is always made of a combination of copper and zinc, has a gold-like appearance a high malleability and workability, and a good resistance to corrosion (Igelegbai et al. 2017). In ancient documents, the term "brass" is often used to denote bronze, the alloy of copper with tin (Ruhland 2002). No bronze bits were identified in the present study.

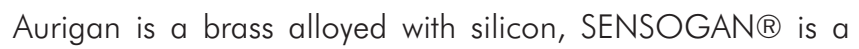
brass alloyed with manganese, a new bit material developed by the equestrian enterprise Sprenger (Anonymus 2019b). SENSOGAN ${ }^{\circledR}$ is the result of additional development of the original material, Aurigan. The composition of copper, manganese and zinc in SENSOGAN ${ }^{\circledR}$ is reported to result in a more regulated process of oxidation of the material within the horse's mouth (Anonymus 2019b).

The elemental composition of Aurigan indicated by the manufacturer (mean Cu $85 \%$, Zn $11 \%$, Si $4 \%$ ) was similar to our results (mean Cu $87 \%$, Zn 12\%, Si 6\%). Literature definition (Bruker 2015) of SENSOGAN® is for example 40-100\% copper, $0.1-40 \%$ zinc and $0-5.5 \%$ manganese. In the present study, more concise ranges could be defined for the different alloy groups with the clustering method (Table 2).

Analysis of changes in the iron content and weight losses of bits by normal wear showed that the iron content did not change significantly over three months, neither in the conventional, nor in the sweet iron bits. Several riders asked the Swiss Equestrian Sport Federation, if sweet iron bits release toxic amounts of iron (Dreier, personal communication). Iron toxicosis followed by a hepatopathy has been reported in horses after supplementation with a vitamin-mineral supplement containing ferrous sulphate for 6 weeks $10.6 \mathrm{mg}$ iron $/ \mathrm{kg}$

Table 4 Weight (g) of conventional $(n=10)$ and sweet iron $(n=9)$ bits over 90 days during normal wear. | Gewicht der konventionellen und der Sweet Iron-Gebisse über einen Zeitraum von 90 Tagen bei normaler Nutzung.

\begin{tabular}{c|cc|cc}
\hline Day & \multicolumn{2}{|c|}{ Conventional bits $(\mathrm{n}=10)$} & \multicolumn{2}{|c}{ Sweet Iron bits $(\mathrm{n}=9)$} \\
\hline & \multicolumn{2}{|c|}{$\begin{array}{c}\text { Mean } \\
\text { weight }(\mathrm{g})\end{array}$} & sd & \multicolumn{2}{|c}{$\begin{array}{c}\text { Mean } \\
\text { weight }(\mathrm{g})\end{array}$} & $\mathrm{sd}$ \\
\hline 0 & 364.8 & 19.4 & 295.9 & 64.4 \\
28 & 364.7 & 19.4 & 295.8 & 64.4 \\
60 & 364.8 & 19.5 & 295.8 & 64.4 \\
90 & 364.5 & 19.4 & 295.7 & 64.4 \\
\hline
\end{tabular}

sd $=$ standard deviation 
body weight/day) (Casteel 2001). However, the iron in bits is almost completely oxidised and considerable release cannot be expected. In the present study the iron content in $\%$ did not change significantly over 90 days, so that the expectation can be supported.

In contrast, the weight loss was significant $(p<0.05)$ in the sweet iron (average loss $0.2 \mathrm{~g}$ ) and the conventional bits (average loss $0.28 \mathrm{~g}$ ) during 90 days of use, which corresponds to an average weight loss of 0.8 to $1.12 \mathrm{~g}$ in a year. The oldest conventional bit analysed was 42 months in use, so that the average weight of $264.8 \mathrm{~g}$ would have decreased to $262 \mathrm{~g}$ after that time. Bit marks are a sign of the high pressure applied by the horse's teeth on the metal bits and are probably more important than the absolute weight losses, as their location may help to identify how the horse reacts orally to the presence of a bit within its mouth (Doherty et al. 2016).

\section{Conclusion}

XRF spectrometry was shown to be a simple and reliable method to analyse the metallic composition of bits. In the present study, the statistical clustering method allowed to better characterise the different alloy groups according to narrower ranges of elements. Of the 103 bits studied, 93 could be attributed to one of the six principal alloy groups identified with this approach. The composition of the steel, stainless steel and brass alloys showed that the bits were of good quality and no toxic heavy metals such as cadmium or lead were identified. No toxic release of iron into the horse's mouth from sweet iron bits is to be expected.

\section{Acknowledgements}

We thank the equestrian shops who allowed us to analyse their bit assortment.

We would further like to thank the riders and horse owners who participated in the field test and Dr Marco Herrmann for his support.

\section{References}

Anonymus (2019a) Free Alloy App for elemental and concentration data of common metal alloys. Bruker Corporation, 40 Manning Road, Billerica, MA 01821, https://www.bruker.com/de/products/x-ray-diffraction-and-elemental-analysis/handheld-xrf/alloy-app.html

Anonymus (2019b) Sensogan ${ }^{\circledR}$, Herm. Sprenger GmbH Metallwarenfabrik, https://pferdesport.sprenger.de/sensogan

Casteel S. W. (2001) Metal toxicosis in horses. Toxicology 17, $517-$ 527; DOI 10.1016/S0749-0739(17)30049-4
Doherty O., Casey V., McGreevy P., McLean A., Parker P., Arkins S. (2017) An analysis of visible patterns of horse bit wear. J. Vet. Behav. 18, 84-91; DOI 10.1016/i.jveb.2016.12.007

Esterson E. (2014) The ultimative book of horse bits. NY, USA: Skyhorse publishing

Gigante G. E., Cesareo R. (1998) Non-destructive analysis of ancient metal alloys by in situ EDXRF transportable equipment. Radiat. Phys. Chem. 51, 689-700; DOI 10.1016/S0969-806X(97)00241-7

Guzzo N., Sartori C., Stelletta C., Bailoni L., Mantovani R. (2018) Comparison between stainless steel and titanium snaffle bits in sport horses during show jumping exercise. J. Equine Vet. Sci. 71,105-111; DOI 10.1016/i.jevs.2018.09.011

Haudrechy P., Mantout B., Frappaz A., Rousseau D., Chabeau G., Faure M., Claudy A. (1997) Nickel release from stainless steels. Contact Derm. 37, 113-117

Hull M. W. (2017) Accuracy, Precision and Confidence in X-ray Fluorescence for Positive Material Identification. Technic. Newsl. 16, $1-6$

Igelegbai E., Oluwaseun A., Adeodu A. O., Daniyan I. A. (2017) Evaluation of Mechanical and Microstructural Properties of $\alpha$-Brass Alloy Produced from Scrap Copper and Zinc Metal through Sand Casting Process. Journal of Minerals and Materials Characterization and Engineering, 5, 18-28; DOI 10.4236/jmmce. 2017.51002

Longoni A., Fiorini C., Leutenegger P., Sciuti S., Fronterotta G., Strüder L., Lechner P. (1998) A portable XRF spectrometer for non-destructive analyses in archaeometry. Nucl. Instrum. Meth. Physics Res. A 409, 407-409

Liu X., Chu P. K., Ding C. (2005) Surface modification of titanium alloys and related materials for biomechanical applications. Master Sci. Eng. Rep. 47, 49-121; DOI 10.1016/i.mser.2004.11.001

McGreevy P., McLean A., Buckley P., McConaghy F., McLean C. (2010) How riding may affect welfare: What the equine veterinarian needs to know. Equine Vet. Educ. 23, 531-539; https://doi. $\mathrm{org} / 10.1111 / \mathrm{j} .2042-3292.2010 .00217 . x$

McGuire M. F. (2001) Austenitic Stainless Steels. Encyclopedia of Materials: Science and Technology 2,406-410; DOI 10.1016/ B0-08-043152-6/00081-4

Melquiades F. L., Appoloni C. R. (2004) Application of XRF and field portable XRF for environmental analysis. J. Radioanal. Nucl. Chem. 262, 533-541

Nazifi S., Eskandarzade N., Khosravi M., Haddadi M., Rahsepar M. (2017) Serum Concentrations of Strontium, Lead, Nickel, Vanadium and Aluminum in Horses. Vet. Sci. Technol, 8, 4; DOI 10.4172/2157-7579.1000457

R Core Team (2018) R: A language for statistical computing. Vienna, Austria; https://www.R-project.org.

Ruhland M. (2002) Antiquing of brass, copper, and bronze. Metal Finish. 100, Suppl. 1, 442-455

Thevis M., Machnik M., Schenk I., Krug O., Piper T., Schänzer W., Düe M., Bondesson U., Hedeland M. (2016) Nickel in equine sports drug testing - pilot study on urinary nickel concentrations. Rapid Com. Mass Spectrom. 30, 982-984; DOI 10.1002/rcm.7528

Torres F., das Gracas M., Melo M., Tosti A. (2009) Management of contact dermatitis due to nickel allergy: an update. Clin. Cosmet. Investig. Dermatol. 2, 39-48

Yuan J., Wei L., Wang C., Ma C., Chen L., Chen D. (2015) Nickel Release Rate of Several Nickel-containing Stainless Steels for Jewelries. J. Iron Steel. Res. Int. 22, 72-77; DOI 10.1016/S1006706X(15)60012-7 